\title{
Longitudinal Data on Flipped Class Effects on Performance in CS1 and Retention after CS1
}

\author{
Celine Latulipe, Audrey Rorrer, Bruce Long \\ University of North Carolina at Charlotte \\ Charlotte, NC \\ \{clatulip,arorrer,nblong\}@uncc.edu
}

\begin{abstract}
We present results of a college wide undergraduate retention study tracking student retention in computing, comparing students who experience a flipped, active learning version of CS1 against those who experience a traditional lecture and lab version of CS1. We examine demographic subgroups to understand retention differences between sexes and racial/ethnic groups. Specifically, we examine which students exit computing majors in the semester immediately after taking CS1, and those who leave following one academic year. This allows us to focus on how the immediate experience of the CS1 teaching approach impacts desire to continue in computer science during the critical first year in CS. Our dataset includes 698 CS majors who took CS1 in either the flipped or traditional style, between Fall 2013 and Fall 2016, at a large, comprehensive, urban research university in the US. Our results show that women were less likely to switch majors after taking the flipped version than after taking the traditional version. Conversely, male students were more likely to be retained following the traditional course, and less likely to be retained following the flipped course. Performance of CS majors in CS1, as measured by DFW rates, is statistically higher in the flipped classes than performance in the traditional classes. Oneyear retention in the major for under-represented groups (women and racial minorities) was higher in the flipped classes for new freshmen taking CS1, but not for transfer students.
\end{abstract}

\section{KEYWORDS}

flipped classes, lightweight teams, retention, sex, gender, race, CS1

ACM Reference Format:

Celine Latulipe, Audrey Rorrer, Bruce Long. 2018. Longitudinal Data on Flipped Class Effects on Performance in CS1 and Retention after CS1. In SIGCSE '18: The 49th ACM Technical Symposium on Computer Science Education, Feb. 21-24, 2018, Baltimore, MD, USA. ACM, New York, NY, USA, 6 pages. https://doi.org/https://doi.org/10.1145/3159450.3159518

\section{INTRODUCTION}

There is a growing trend towards fully or partially flipping introductory computer science courses and employing active learning techniques during class time [6, 11, 16, 17, 23]. In fully flipped classes, students absorb the informational content outside of the classroom through short videos, readings, interactive textbooks,

Permission to make digital or hard copies of part or all of this work for personal or classroom use is granted without fee provided that copies are not made or distributed for profit or commercial advantage and that copies bear this notice and the full citation on the first page. Copyrights for third-party components of this work must be honored.

For all other uses, contact the owner/author(s).

SIGCSE '18, Feb. 21-24, 2018, Baltimore, MD, USA

(c) 2018 Copyright held by the owner/author(s)

ACM ISBN 978-1-4503-5103-4/18/02.

https://doi.org/https://doi.org/10.1145/3159450.3159518 etc., and then apply that learning in the classroom through active learning activities, often in collaboration with peers. Students in flipped classes get to try applying their knowledge in a classroom setting, surrounded by peers, teaching assistants (TAs) and instructors, which means that they have help when they get stuck. Getting stuck in CS1 can take on many forms: students may not know the right syntax, may not understand how a programming feature applies to a given problem, or may not understand how to interpret a compiler error, or how to logically construct a solution. While help may be available online for some problems, that help is out of context. By facing these problems in the classroom with others working through the same activity, peers can learn from each other and receive contextually-sensitive help. This can reduce the high levels of frustration that can occur while working in isolation.

The peer interaction that is often part of flipped class structures, beyond being useful for helping students get 'unstuck', can provide many other benefits. Students get practice with social interaction and teamwork, and also communication practice within their discipline. In earlier work, we presented the 'Lightweight Teams' structure for flipped classes, which specifies that students are put into teams with a fixed seating arrangement for the entire semester [14]. The teams are lightweight, meaning that there is no significant assignment or project that the teams have to do together. They only work on low-stakes active learning activities while in class. This takes away the grade stress that often plagues class project teams, and results in teams that are positively engaged in social learning, rather than coordination headaches and blame games. This model can improve student engagement and learning outcomes in subsequent classes. We argued that by telling students where to sit and who to sit with, we removed significant levels of freshman anxiety associated with entering a large lecture hall. In addition, we showed that students reported making many new friends as a result of the Lightweight Teams structure [14]. We had also hypothesized that such a structure, because of the many new friends, would result in students being retained in the major, as they would have developed a strong support network of peers that they could rely on in later computing classes when they faced challenges. However, as we were only able to report early results, we were unable at that time to test the retention hypothesis.

\subsection{Local Context}

The University of North Carolina at Charlotte is a large, urban campus with more than 29,000 undergraduates, which serves the local state population, drawing mostly from the greater metropolitan area. We are a minority-serving institution ${ }^{1}$, with more than $25 \%$

${ }^{1}$ Characteristics of Minority-Serving Institutions and Minority Undergraduates Enrolled in These Institutions, U.S. Department of Education, NCES 2008-156 
Table 1: Flipped vs. Traditional CS1 Class at our institution

\begin{tabular}{|l|l|l|}
\hline \hline & Traditional Class & Flipped Class \\
\hline Homework & Assigned Readings & Videos, Readings, Prepwork Quiz \\
Class Activities & Lecture & Active Learning Peer Instruction Quizzes and Activities \\
Class Sizes & $60-200$ & $80-126$ \\
Teams & None & Lightweight Teams for whole semester \\
Seating & Arbitrary & Assigned \\
Setting* & Lecture Halls and Classrooms & Classrooms and Active Learning Classrooms \\
Labs & individual or paired programming & Gender-paired programming \\
Lab Sizes & $20-24$ & $35-45$ \\
Language & Java (C++ before 2015) & Java \\
\hline
\end{tabular}

of freshman students identifying as African American or Hispanic. The average age of our undergraduate student population is 25 ; half our new students are transfers, a population that is likely to have adult obligations and time constraints.

Our computing college has experienced a $62 \%$ increase in undergraduate enrollment over the last five years, from 995 to 1616 in 2016. The introductory courses offered in our college enroll approximately 200 students each semester, most of whom are first year students, i.e. freshmen and transfer students. Many students arrive unprepared to learn programming for a myriad of reasons, e.g. lack of pre-course exposure to programming, and college readiness in general. As a result, it is not surprising that the percentage of students receiving D, F, and $\mathrm{W}$ grades is high, at an average of $40 \%$ for CS1. Many students have to repeat these gateway courses, and low performers are ill-prepared for higher level course work.

Retention among the CS freshmen and transfer student populations has tended to fluctuate, rather than show a steady rise. One-year new freshmen retention bounced from $71 \%$ in 2012 , to a high of $82 \%$ in 2014, and down to $73 \%$ in 2015 . Two-year freshmen retention rates are at $60 \%$. For female students, since 2012, we have lost $29-37 \%$ of new freshmen and transfers after one year. For minority students, we lose over half after their first year: $64 \%$ of new freshmen and new transfers did not return to the major one year later in 2015. In an effort to address these issues, we have created a set of flipped introductory CS courses in our college. To set the stage for the analysis presented in this paper, Table 1 presents the similarities and differences between the flipped class and traditional versions of CS1, which is our focus.

In this work, we present data collected over four years that compares one-semester and one-year retention in the major rates for both freshmen and transfer students who took either a flipped CS1 or a traditional CS1. Our data is broken down by sex and race so we can report retention rates across those demographics. We do not report graduation rates at this point, as at our institution very few students graduate within four years, with most graduating in the fifth or sixth year. We also report on class performance (DFW rates) across flipped vs. traditional classes, for all CS1 students.

\section{RELATED WORK}

\subsection{Retention Issues in CS}

Failure rates in introductory programming courses are generally between $30-50 \%$ worldwide [2], though most data on failure rates tends to be anecdotal rather than systematic [26]. Some have argued that traditional introductory computer programming education fails because it is antisocial, boring, tedious, irrelevant and competitive instead of presented as socially relevant and cooperative [21]. As a result, the number of alternative teaching methods being explored in CS education is increasing, with many promising approaches. Active learning, online learning, hybrid learning, social learning are just a few of the popular methods being discussed, tried, and adapted for teaching CS. Yet the effect of these new teaching methods, along with a deeper understanding of the impact of interventions on specific student populations remains unclear.

Luxton-Reilly argues that the retention problem in early college computing courses relates to unrealistic expectations that students can learn how to program in a single semester[15]. This is too much too soon, especially for students without a CS course background from high school. In our state, CS courses are not required for a high school diploma or applicable for STEM credit, and many of our students arrive to CS1 with no prior computing experience. In a recent survey of students taking our sophomore-level data structures course, none of the female students and only a minority of the male students had taken a high school computing course.

Climate issues also appear to be a major factor contributing to women and under-represented minorities leaving CS. Women in CS and STEM tend to feel more isolated [24]. Research has shown that ambient cues in the environment of a computer science lab can negatively impact women's feelings of belonging [4].

\subsection{Active Learning and Flipped Classes}

Active learning is not a clear or narrowly defined concept [23], but is a term that encompasses a variety of pedagogical practices that are different from traditional lecturing. Active learning is generally seen as a positive teaching strategy that increases student engagement and gets students more involved in the process of learning [20,25]. Pair programming, an active learning strategy with a long history in computing, is shown to improve retention in CS1 [17]. One of the most common active learning techniques is peer instruction activities in which students engage together in answering multiplechoice questions posed by the instructor. Peer instruction has been shown to increase student self-efficacy in CS1 classes [27]. Peer instruction is considered a 'best practice' for CS1 classes [22].

Research on flipped classes in computing has increased, and most report positive results $[3,11,12,14]$. Flipping the classroom 
provides a structure in which the majority of in-class time can be devoted to active learning strategies [16]. Research suggests that creating a structured learning environment with active learning, as exemplified in most flipped classrooms, provides better results across all demographic groups, but is especially helpful to underrepresented groups and first-generation college students [8]. Some research from the life sciences has shown that the effectiveness of flipped classroom structures are due to the better pre-class preparation that the structure enforces [10]. Research has also shown that the flipped classroom structure, with significant peer interaction, improves students' perceptions of their creative fluency [1].

\subsection{Team-based Learning}

Team-based learning has been shown to have positive pedagogical results across a variety of domains $[18,19]$. The benefits of team-based learning include communication practice, exposure to multiple perspectives, and the ability to attack larger problems. Much of the previous work on team-based learning concerns project teams in which students in a class are assigned to groups so that they can work together on an assignment or large project, that may last a few weeks up to an entire semester. This type of project team is typically not useful in CS1 courses where students haven't yet acquired basic programming skills. The lightweight teams approach we introduced [14] allows CS1 students to benefit from peer instruction and social interaction, but the teams do not have any assignments or projects that they have to complete together. The teams are lightweight because the grade weights related to team activities are extremely low. The teams sit together throughout the semester and work on in class active learning activities together.

The Lightweight Teams approach echoes the socio-academic integrative moments theory advanced by Deil-Amen [7]. This theory was developed to capture the experience of two-year community college students for whom the social aspects of the college experience are limited, and for whom the community that they belong to is their home community, not the college community. These students, who typically commute to college between work and other commitments, do not tend to get involved in student organizations on campus. Thus, the ability for them to become socially integrated into the college community is greatly diminished and the only opportunity they may have to develop a campus community is through interaction with students and faculty during class times. Flipped, active learning classes are more likely to provide this type of socio-academic integrative moment than lecture classes.

\section{RESEARCH QUESTIONS}

The research questions we address are how the flipped vs. traditional class approach differs in terms of student performance, and how these two approaches impact retention in the major. In this paper we investigate retention rates based on students' first university exposure to a CS class. We investigate student retention for two groups of CS1 students: those who took a flipped, lightweight teams version vs. those who took a traditional lecture version.

\section{METHODS}

We requested anonymized data from the Institutional Research Office at our institution. In our analysis, the independent variable is the instructional dimension: whether students took their initial CS1 course as a flipped class with lightweight teams or a traditional lecture and lab. The dependent variable is the percentage of students who switched out of their CS major. This dependent variable can be broken down across various dimensions:

- Enrollment Dimension: New Freshman vs. Transfer Students. Students entering CS majors are classified as new freshmen (first time university students, entering directly from high school) or transfer students (from other colleges or universities who have declared a CS major). Roughly half the incoming students each year are new freshman.

- Sex Dimension: Male vs. Female. Our university allows two sex classifications at enrollment, male or female, and does not capture chosen gender identity.

- Racial/Ethnic Dimension: Underrepresented Minority Groups. Underrepresented minority groups in this study are defined as African American, Hispanic/Latino, Native American, Multi-ethnic, and Pacific Islander. Caucasian and Asian students define the majority group. International students and the unknown classifications are omitted from this study because the numbers are extremely small.

For the academic performance analysis, all students who enrolled in CS1 during fall and spring terms between 2013 and 2017 were included. There were 166 students in the flipped version, and 1573 in the traditional version. Grade performance was analyzed by pass $(\mathrm{A}, \mathrm{B}, \mathrm{C})$ or fail $(\mathrm{D}, \mathrm{F}, \mathrm{W})$.

\section{RESULTS}

In this section we present both descriptive results on retention in CS across the dimensions of freshmen vs. transfer students, males vs. females, racial/ethnic background, and interactions across these. Our independent variable is retention in the major immediately after taking either the flipped or traditional CS1 class. For all the statistics below, the number of students in each category is the number of students who completed the CS1 course, except where we specifically discuss DFW rates.

\subsection{Descriptive Results}

In these descriptive statistics, we show results for students who changed out of the major, but these do not include students who dropped out of university entirely. The raw data in Table 2 shows that no females changed major out of CS after CS1 flipped, but 7\% of males did. For CS freshmen that took the traditional CS1 class, $3 \%$ of females changed major and $3 \%$ of males changed major.

If we look at the impact on racial/ethnic minorities, no minorities changed majors out of CS after taking the flipped CS1, while $5.3 \%$ of asian and white students changed major out of CS after taking the flipped CS1. In contrast, $5 \%$ of minority CS majors changed major after taking the traditional CS1, while only $2 \%$ of asian and white CS majors changed out of the major after taking traditional CS1. Note that this data represents only students taking our CS1 class who had already selected a CS major. Our CS1 classes often have many students from other majors. 
Table 2: Count of CS freshmen (not transfer) students completing CS1 and count of students changing major out of CS next term, from Spring 2013-Spring 2016, by sex, majority vs minority group and instructional method

\begin{tabular}{|l|l|r|r||r|r|r|r|}
\hline \multicolumn{2}{|l|}{} & \multicolumn{2}{|c|}{ All CS Freshmen } & \multicolumn{2}{c|}{ Afr-Amer \& Hisp } & \multicolumn{2}{c|}{ Asian \& White } \\
\hline Type & Sex & \# Completed & $\begin{array}{r}\text { \# Changed } \\
\text { Major }\end{array}$ & \# Completed & $\begin{array}{r}\text { \# Changed } \\
\text { Major }\end{array}$ & \# Completed & $\begin{array}{r}\text { \# Changed } \\
\text { Major }\end{array}$ \\
\hline Flipped & Female & 29 & 0 & 6 & 0 & 22 & 0 \\
& Male & 70 & 5 & 11 & 0 & 53 & 4 \\
& Total & 99 & 5 & 17 & 0 & 75 & 4 \\
\hline Traditional & Female & 69 & 2 & 15 & 1 & 41 & 1 \\
& Male & 530 & 14 & 82 & 4 & 404 & 10 \\
& Total & 599 & 16 & 97 & 5 & 445 & 11 \\
\hline
\end{tabular}

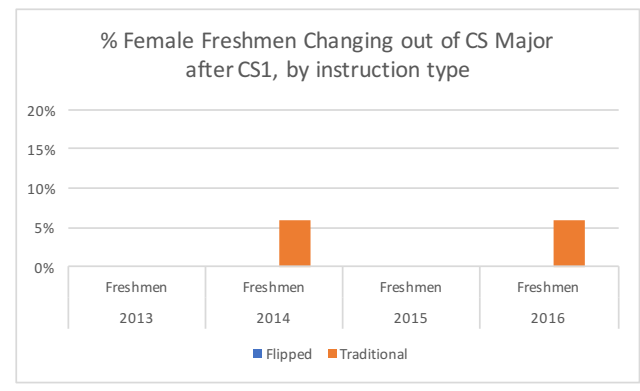

Figure 1: The \% of freshman female CS majors who change major immediately after CS1, by instructional method.

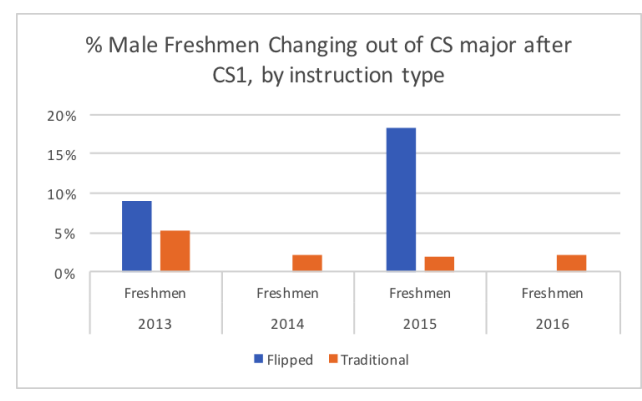

Figure 2: The \% of freshman male CS majors changing out of the major immediately after CS1, by instructional method.

\subsection{Statistical Analysis}

To analyze retention by course type, a series of non-parametric analyses were conducted. First, students were grouped by admission type (freshmen/transfer), by sex (male/female), and by underrepresented minority group, and then by retention status. Retention is defined as continuing in the major; not-retained is defined as changing out of CS or leaving the university. Due to small numbers in some cases, statistical analyses were not possible, so a second series of non-parametric analyses were performed, that combined female students into the underrepresented minority group. Underrepresented Minority Group students are indicated by URM, and include non-white and non-asian students. Underrepresented Student Group (URS) includes all URM students and white and asian

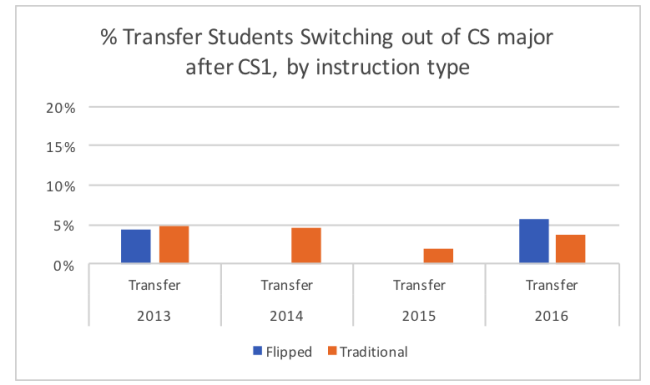

Figure 3: The \% of transfer CS students changing out of the major immediately after CS1, by instructional method.

women. Each analysis was conducted for retention after one year in the major, and repeated for retention in the term following taking CS1. Figure 4 displays the analyses that were performed and bolds those with statistically significant findings.

5.2.1 Academic Performance. For all CS majors who enrolled in CS1 during fall and spring terms between 2013 and 2017 (freshmen and transfers), there were 166 students in the flipped version, and 1573 in the traditional version. Grade performance was analyzed by pass (A,B,C) or fail (D,F,W), and chi square revealed statistically significant differences in performance outcomes among the courses, $x(1)=6.369, p=.012$. More students passed flipped CS1 than expected, and fewer passed traditional CS1 than expected.

5.2.2 One Year Retention. Underrepresented minority students in computing (women, African American, Hispanic, Native American, Pacific Islander and Multi-racial) were compared to majority students (white and asian males) in one year retention in the computing major having taken the flipped course or the traditional course. Statistically significant differences were observed for transfer students, $x(1)=4.153, p=.042$; fewer transfer underrepresented minority students were retained in the flipped course than expected while more were retained in the traditional course than expected. New freshmen underrepresented minority students were retained significantly higher than expected in the flipped course than the traditional course, $x(1)=16.202, p=.000$.

When the student groups were further separated by sex and then by underrepresented minority ethnicity (African American, Hispanic, Native American, Pacific Islander, Multi-ethnic vs Majority), 


\begin{tabular}{|c|c|c|c|}
\hline \multicolumn{4}{|c|}{ Non-parametric Analyses Performed by Population } \\
\hline \multicolumn{4}{|c|}{ R1. Are 1-year retention rates in CS different based upon taking Flipped vs Traditional CS 1 Course? } \\
\hline Overall & \multicolumn{3}{|c|}{ Freshmen Retained/Not-Retained } \\
\hline Gender & $\begin{array}{l}\sim \text { Freshmen Females Retained/Not-Retained } \\
\text { Transfer Females Retained/Not-Retained } \\
\text { Freshmen Females/Males, Retained/Not-Retained } \\
\text { Transfer Females/Males, Retained/Not-Retained }\end{array}$ & URM & $\begin{array}{l}\sim \text { Freshmen URM Retained/Not-Retained } \\
\text { Transfer URM Retained/Not-Retained } \\
\text { Freshmen URM/Majority, Retained/Not-Retained } \\
\sim \text { Transfer URM/Majority, Retained/Not-Retained }\end{array}$ \\
\hline \multicolumn{2}{|r|}{ Females + URM $=$ Underrepresented Students } & \multicolumn{2}{|c|}{$\begin{array}{l}\sim \text { Freshmen URS Retained/Not-Retained } \\
\text { Transfer URS Retained/Not-Retained } \\
\text { Freshmen URS/Majority, Retained/Not-Retained } \\
\text { Transfer URS/Majority, Retained/Not-Retained }\end{array}$} \\
\hline \multicolumn{4}{|c|}{ R2. Are Next-Term retention rates in CS different based upon taking Flipped vs Traditional CS 1 Course? } \\
\hline Overall & $\begin{array}{l}\text { Freshmen Retained/Not-Retained } \\
\text { Transfer Retained/Not-Retained }\end{array}$ & & \\
\hline Gender & $\begin{array}{l}\sim \text { Freshmen Females Retained/Not-Retained } \\
\text { Transfer Females Retained/Not-Retained } \\
\text { Freshmen Females/Males, Retained/Not-Retained } \\
\text { Transfer Females/Males, Retained/Not-Retained }\end{array}$ & URM & $\begin{array}{l}\sim \text { Freshmen URM Retained/Not-Retained } \\
\sim \text { Transfer URM Retained/Not-Retained } \\
\text { Freshmen URM/Majority, Retained/Not-Retained } \\
\sim \text { Transfer URM/Majority, Retained/Not-Retained }\end{array}$ \\
\hline \multicolumn{2}{|r|}{ Females + URM $=$ Underrepresented Students } & \multicolumn{2}{|c|}{$\begin{array}{l}\sim \text { Freshmen URS Retained/Not-Retained } \\
\text { Transfer URS Retained/Not-Retained } \\
\text { Freshmen URS/Majority, Retained/Not-Retained } \\
\text { Transfer URS/Majority, Retained/Not-Retained }\end{array}$} \\
\hline
\end{tabular}

Figure 4: Summary of Non-parametric analysis by population. Items in bold represent statistically significant relationships, while items marked represents populations with too few students in flipped cells for analysis.

statistically significant differences were again observed. Female students were retained at a higher rate than expected when taking the flipped course and less than expected when taking traditional course, $x(1)=22.347, p=.000$, while male students were retained at a higher rate in the traditional course than in the flipped course. For minority ethnicity transfer students, fewer were retained than expected in the flipped course and more than expected in the traditional course, $x(1)=, 3.859, p=.049$.

5.2.3 Next Term Retention. When next term retention of all new freshmen was compared by sex and course, a statistically significant difference was obtained, $x(1)=20.992, p=.000$. Female students were retained at a higher rate than expected when taking the flipped course and less than expected when taking the traditional course, whereas male students were retained more than expected in the traditional course. When transfer students were compared by sex and course, female students were retained more than expected in the flipped course with less retained in the traditional course; the opposite was found for males, who were retained at a higher rate than expected in the traditional course, $x(1)=10.339, p=.001$.

Underrepresented minority students in computing (women, African American, Hispanic, Native American, Pacific Islander and Multi-racial) were compared to majority students who haven taken the flipped course or the traditional course. Statistically significant differences were observed for freshmen students, $x(1)=7.892, p=$ .005 ; more underrepresented students were retained in the flipped course than expected, and fewer in the traditional, with fewer majority students retained in both the flipped course and traditional course than expected. Fewer transfer underrepresented minority students were retained in the flipped course than expected while more were retained in the traditional course than expected.

\section{DISCUSSION}

Our findings suggest that female and underrepresented minority group students are retained at higher rates when taking a flipped CS1 course when entering as freshmen, and no female students left the major after taking a flipped introductory course. This is unsurprising given that we know female and minority students have been shown to have higher retention in computing when they can develop a sense of community [5]. What is surprising is that majority male students were retained better in traditional CS1 courses, because researchers have suggested that what works well for underrepresented students will work equally as well for majority students $[9,13]$. We interpret these findings as strong indications that one size does not fit all students, and that further study is needed to parse out impact of instructor, student prior computing exposure, and other possible confounding variables on retention. Faculty advisors should inform students about their choice of course style so that they can make the most appropriate decision for their own personal preference. The findings that minority transfer students did not reap the retention benefits from flipped courses may be because their identity as transfer student trumps their minority identity. Transfer students are typically older than freshmen, indicative that these students are more mature, and may face pressures of adulthood beyond those of a typical freshman.

The flipped class approach with required prepwork forces students to spend more time learning to program, which may account for some of the success, inline with earlier research [10]. An increase in the time spent on preparation supports the idea that 'programming is easy' but takes time [15]. This is likely especially helpful for students who come in without programming experience.

The social aspects of lightweight teams in our flipped classes means that students see that others also struggle with the new 
concepts. As they see their peers overcome, it gives them confidence and self-efficacy that they also can persevere. This means they are less likely to think they don't fit the CS mold. Because they have made friends, they have people they can call on when they get stuck on something, and study with for tests.

\section{LIMITATIONS}

Our analysis has certain limitations. As with most post-hoc analysis in higher education, there is almost no ability to control for between subjects population confounds, as students tend to select course section based on what suits their schedules. In addition, the institutional data we acquired that is used to understand one-semester and one-year retention effects is based on students who passed the CS1 class, ignoring the students who may have failed these classes and left (though this is captured in the DFW analysis). Institutional enrollment numbers hide non-gender binary students, requiring them to select a binary sex category.

As with all educational research, there are contextual confounds. Our introductory CS courses have been in flux, with a move to make all CS1 classes taught in Java, though some of the courses represented in our data were taught with $\mathrm{C}++$. Additionally, we did not control for instructors as variables, and many of the traditional courses have begun to be redesigned to incorporate some degree of active learning activities. As enrollments increase over time, we anticipate being able to control for instructor variables, such as experience with and usage level of active learning techniques.

\section{CONCLUSIONS}

We have presented a longitudinal analysis based on four years of data that examines how flipped vs. traditional CS1 classes impact student retention in the following year. We showed that female students and underrepresented racial minority students are less likely to switch out of the CS major after taking a flipped version of CS1, while the opposite is true for male students and transfer students. We also showed that female students and under-represented minority students were less likely to fail a flipped version of CS1.

\section{ACKNOWLEDGMENTS}

This work is supported by the National Science Foundation, IUSE/Professional Formation of Engineers: Revolutionizing engineering and computer science Departments (RED), Award 1519160.

\section{REFERENCES}

[1] A. M. Al-Zahrani. From passive to active: The impact of the flipped classroom through social learning platforms on higher education students' creative thinking. British fournal of Educational Technology, 46(6):1133-1148, 2015.

[2] J. Bennedsen and M. E. Caspersen. Failure rates in introductory programming. SIGCSE Bull., 39(2):32-36, June 2007.

[3] J. Bergmann and A. Sams. Flip your classroom: Reach every student in every class every day. International Society for Technology in Education, 2012.

[4] S. Cheryan, V. C. Plaut, P. G. Davies, and C. M. Steele. Ambient belonging: how stereotypical cues impact gender participation in computer science. Fournal of personality and social psychology, 97(6):1045, 2009.

[5] T. Dahlberg, T. Barnes, K. Buch, and A. Rorrer. The stars alliance: Viable strategies for broadening participation in computing. ACM Transactions on Computing Education (TOCE), 11(3):18, 2011.

[6] S. L. Dazo, N. R. Stepanek, R. Fulkerson, and B. Dorn. An empirical analysis of video viewing behaviors in flipped cs1 courses. In Proceedings of the $2016 \mathrm{ACM}$ Conference on Innovation and Technology in Computer Science Education, ITiCSE '16, pages 106-111, New York, NY, USA, 2016. ACM.
[7] R. Deil-Amen. Socio-academic integrative moments: Rethinking academic and social integration among two-year college students in career-related programs. The fournal of Higher Education, 82(1):54-91, 2011.

[8] S. L. Eddy and K. A. Hogan. Getting under the hood: how and for whom does increasing course structure work? CBE-Life Sciences Education, 13(3):453-468, 2014.

[9] J. Goode and J. Margolis. Exploring computer science: A case study of school reform. ACM Transactions on Computing Education (TOCE), 11(2):12, 2011.

[10] D. Gross, E. S. Pietri, G. Anderson, K. Moyano-Camihort, and M. J. Graham. Increased preclass preparation underlies student outcome improvement in the flipped classroom. CBE-Life Sciences Education, 14(4):ar36, 2015.

[11] N. A. Hamid. A functional flipped CS1. f. Comput. Sci. Coll., 32(2):120-126, Dec. 2016.

[12] D. Horton, M. Craig, J. Campbell, P. Gries, and D. Zingaro. Comparing outcomes in inverted and traditional CS1. In Proceedings of the 2014 Conference on Innovation \& Technology in Computer Science Education, ITiCSE '14, pages 261-266, New York, NY, USA, 2014. ACM.

[13] G. Ladson-Billings. Culturally relevant pedagogy 2.0: aka the remix. Harvard Educational Review, 84(1):74-84, 2014.

[14] C. Latulipe, N. B. Long, and C. E. Seminario. Structuring flipped classes with lightweight teams and gamification. In Proceedings of the 46th ACM Technical Symposium on Computer Science Education, SIGCSE '15, pages 392-397, New York, NY, USA, 2015. ACM.

[15] A. Luxton-Reilly. Learning to program is easy. In Proceedings of the 2016 ACM Conference on Innovation and Technology in Computer Science Education, ITiCSE '16, pages 284-289, New York, NY, USA, 2016. ACM.

[16] M. L. Maher, C. Latulipe, H. Lipford, and A. Rorrer. Flipped classroom strategies for CS education. In Proceedings of the 46th ACM Technical Symposium on Computer Science Education, SIGCSE '15, pages 218-223, New York, NY, USA, 2015. ACM.

[17] C. McDowell, L. Werner, H. E. Bullock, and J. Fernald. Pair programming improves student retention, confidence, and program quality. Commun. ACM, 49(8):90-95, Aug. 2006.

[18] L. K. Michaelsen, A. B. Knight, and L. D. Fink. Team-based learning: A transformative use of small groups. Greenwood Publishing Group, 2002.

[19] L. K. Michaelsen and M. Sweet. Fundamental principles and practices of teambased learning. Team-based learning for health professions education: A guide to using small groups for improving learning. Sterling (VA): Stylus Publishing, pages 9-31, 2008

[20] J. Pirker, M. Riffnaller-Schiefer, and C. Gütl. Motivational active learning: Engaging university students in computer science education. In Proceedings of the 2014 Conference on Innovation \& Technology in Computer Science Education, ITiCSE '14, pages 297-302, New York, NY, USA, 2014. ACM.

[21] L. Porter, M. Guzdial, C. McDowell, and B. Simon. Success in introductory programming: What works? Commun. ACM, 56(8):34-36, Aug. 2013.

[22] L. Porter and B. Simon. Retaining nearly one-third more majors with a trio of instructional best practices in CS1. In Proceeding of the 44th ACM Technical Symposium on Computer Science Education, SIGCSE '13, pages 165-170, New York, NY, USA, 2013. ACM.

[23] K. Sanders, J. Boustedt, A. Eckerdal, R. McCartney, and C. Zander. Folk pedagogy: Nobody doesn't like active learning. In Proceedings of the 2017 ACM Conference on International Computing Education Research, ICER '17, pages 145-154, New York, NY, USA, 2017. ACM.

[24] P. Sankar, J. Gilmartin, and M. Sobel. An examination of belongingness and confidence among female computer science students. SIGCAS Comput. Soc., 45(2):7-10, July 2015.

[25] A. Vihavainen, J. Airaksinen, and C. Watson. A systematic review of approaches for teaching introductory programming and their influence on success. In Proceedings of the Tenth Annual Conference on International Computing Education Research, ICER '14, pages 19-26, New York, NY, USA, 2014. ACM.

[26] C. Watson and F. W. Li. Failure rates in introductory programming revisited. In Proceedings of the 2014 Conference on Innovation \& Technology in Computer Science Education, ITiCSE '14, pages 39-44, New York, NY, USA, 2014. ACM.

[27] D. Zingaro. Peer instruction contributes to self-efficacy in cs1. In Proceedings of the 45th ACM Technical Symposium on Computer Science Education, SIGCSE '14, pages 373-378, New York, NY, USA, 2014. ACM. 